\title{
Angiocentric Immunoproliferative Lesion
}

National Cancer Institute

\section{Source}

National Cancer Institute. Angiocentric Immunoproliferative Lesion. NCI Thesaurus. Code C40970.

A neoplastic lymphoproliferative process characterized by an angiocentric arrangement of the tumor cells which is associated with angiodestruction. It includes lymphomatoid granulomatosis which is a lymphoproliferative lesion derived from mature B-lymphocytes and cases of extranodal NK/T-cell lymphomas of nasal type. 